Research Paper

\title{
Elevated CD36 expression correlates with increased visceral adipose tissue and predicts poor prognosis in ccRCC patients
}

\author{
Wen-Hao $\mathrm{Xu}^{12^{*}}$, Yuan-Yuan $\mathrm{Qu}^{1,2^{*}}$, Jun Wang ${ }^{1,2^{\star}}$, Hong-Kai Wang ${ }^{1,2}$, Fang-Ning Wan ${ }^{1,2}$, Jian-Yuan Zhao ${ }^{3 凶}$, Hai-Liang \\ Zhang ${ }^{1,2 \varpi}$, Ding-Wei $\mathrm{Ye}^{1,2 \varpi}$ \\ 1. Department of Urology, Fudan University Shanghai Cancer Center, Shanghai 200032 \\ 2. Department of Oncology, Shanghai Medical College, Fudan University, Shanghai 20032, P.R. China \\ 3. The Obstetrics \& Gynecology Hospital of Fudan University, State Key Lab of Genetic Engineering, School of Life Sciences and Collaborative Innovation Center of \\ Genetics \& Development, Fudan University, Shanghai 200032, P.R. China \\ ${ }^{*}$ Contribute equally \\ $\triangle$ Corresponding author: Ding-Wei Ye (Email: dwyeli@163.com) \& Hai-Liang Zhang (Email: zhanghl918@163.com) Department of Urology, Fudan University Shanghai \\ Cancer Center, No. 270 Dong'an Road, Shanghai, 200032, People's Republic of China. Tel: 86-21-64175590-2805 Fax: 86-21-64434556; Prof. Jian-Yuan Zhao, Ph.D. (Email: \\ zhaojy@fudan.edu.cn) The State Key Laboratory of Genetic Engineering and Collaborative Innovation Center of Genetics \& Development, School of Life Sciences, Fudan \\ University, No. 2005 Songhu Road, Shanghai 200433, People's Republic of China Tel: 86-21-51630421.
}

(C) The author(s). This is an open access article distributed under the terms of the Creative Commons Attribution License (https://creativecommons.org/licenses/by/4.0/). See http://ivyspring.com/terms for full terms and conditions.

Received: 2018.10.26; Accepted: 2019.06.22; Published: 2019.07.25

\begin{abstract}
Objective: Growing evidence has proved obesity one of the confirmed important etiologic indicators for renal cell carcinoma (RCC). CD36 is underpinned to be involved in adipose absorption, but its role in clear cell renal cell carcinoma (ccRCC) remains unclear. This study aimed to investigate the mRNA expression of $C D 36$ in anthropometric measures of adipose tissue and defining its value in predicting prognosis in $\mathrm{CCRCC}$ patients.
\end{abstract}

Methods: Real-Time qPCR gene expression analysis was detected from 367 paired ccRCC and adjacent normal tissues. Distributions of categorical clinical-pathological data together with levels of CD36 expression were compared with $X^{2}$-test in a contingency table. Subcutaneous adipose tissue (SAT) and visceral adipose tissue (VAT) were measured by magnetic resonance imaging (MRI) and identified at the level of the umbilicus. Pearson's correlation coefficient was utilized to quantify relations between body mass index (BMI), VAT\%, SAT and CD36 expression respectively. Partial likelihood test from univariate and multivariate Cox regression analysis were developed to address the influence of independent factors on progression-free survival (PFS) and overall survival (OS). The Kaplan-Meier method and log-rank test were performed to assess the survival benefits between discrete levels.

Results: In the current study, CD36 mRNA was demonstrated highly expressed in ccRCC compared with normal tissues. In addition, CD36 mRNA expression was significantly increased in patients with advanced TNM stage $(p=0.003, p<0.001, p<0.001)$, and high VAT\% $(p=0.004)$. Pearson's correlation coefficient indicated that CD36 amplification positively correlated with BMI $(r=0.117, p=0.025)$, VAT\% $(r=0.465$, $p<0.001)$, while negatively associated with SAT $(r=-0.296, p=0.002)$. Median PFS was 60 months and OS was 99 months. Meanwhile, ccRCC patients with elevated CD36 expression held shorter PFS and OS, with hazard ratios [HR; 95\% confidence interval $(\mathrm{Cl})$ ] of $4.873(3.300-7.196, p<0.001)$ and 4.610 $(2.956-7.189, p<0.001)$. In 104 cases with available MRI scans, VAT was significantly correlated with poor PFS and OS, with HR of $2.556(1.036-6.310, p<0.042)$ and 3.291 (1.034-10.477, $p<0.044)$. A total of 100 significant genes were obtained from GSEA, and CD36 was found involved in the most significant pathways including fatty acid metabolism, UV response, angiogenesis and transforming growth factor beta (TGF- $\beta$ ) signaling pathways.

Conclusion: In conclusion, our study first reveal that elevated CD36 mRNA expression is positively correlated to distribution of abdominal adipose, particularly VAT\%, which, in addition, notably predicts poor prognosis in ccRCC patients.

Key words: $C D 36$, visceral adipose tissue, subcutaneous adipose tissue, body mass index, clear cell renal cell carcinoma 


\section{Introduction}

Renal cell carcinoma (RCC) has become one of the most common malignancy in the genitourinary system, and accounts approximately $3 \%$ of adult malignant tumors and $2 \%$ of all cancer deaths [1]. The worldwide morbidity and mortality rates of RCC are growing approximately 2-3\% per decade [2]. Until the last few years, the rates are stabilizing or declining in many developed countries [3]. Clear cell renal cell carcinoma (ccRCC) is the most predominant histological subtype of RCC, responsible for about $75 \%$ of cases. The incidence of the disease varies among demographic, geographic, and to a lesser extent, hereditary factors. Nowadays, many prevalence of factors contributing to RCC have been identified, especially obesity and physical inactivity.

Cluster of differentiation 36 (CD36) is encoded by the $C D 36$ gene. As an integral membrane protein present on the surface of various cell types in vertebrate [4], CD36 antigen was involved in adipose metabolism and individual obesity [4-7]. For example, Pepino et al. detected genetic bases for different expression of the CD36 receptor in obese individual, demonstrating significant obesity sensitivity in a significant relationship with expression of CD36 receptor [7]. In 2017, Pascual et al. found CD36 participated in fatty acid intake on the membrane of metastatic tumor cells, including melanoma, breast, bladder, lung and ovarian carcinoma. Interestingly, tumor cells completely stopped metastasis in mouse models when CD36 expression was knockdown [8]. Therefore, CD36 may affect the tumorigenesis of ccRCC through underlying lipid metabolism variations.

Several studies demonstrated that body mass index (BMI) was one of the relative risk factors in ccRCC patients [9-12]. Also, it is noteworthy that BMI is globally accepted as a valid and convenient anthropometric measurement of obesity classifications. Recently, many studies have controversies on the accuracy of BMI for individual body fat assessment and metabolic risk [13-15]. So, it is necessary to introduce new measurements to indicate different body adipose depots, and their potential value in pathogenesis of ccRCC $[16,17]$. In 2010, Ibrahim MM indicated that the anatomy and biological functions distinguished greatly between subcutaneous adipose tissue (SAT) and visceral adipose tissue (VAT) [18]. Different from SAT, VAT is surrounded between organs in abdominal cavity, and was deemed to predispose individual to type II diabetes, inflammation, and other obesity-related diseases [19]. The relationship between VAT and RCC was also reported in recent years. One retrospective study in China found that increased VAT was significantly associated with high Fuhrman grade in patients with clinical T1a RCC [20]. The visceral obesity percentage (VAT\%), calculated using the formula VAT $\%=[($ AP-SAT $) / A P] \times 100 \%$, was deemed significant in clinical research and especially associated with disease recurrence for localized RCC patients [21]. The increasing insights on fat distribution provide promising pathways to predict the occurrence of ccRCC and to further prevent from this malignancy.

To investigate the CD36 mRNA expression in anthropometric measures of abdominal adipose tissue and defining its value in ccRCC patients, we enrolled 367 patients who have received previous radical nephrectomy in our institution. We hypothesized that CD36 mRNA expression correlated with $\mathrm{VAT} \%$, and predicted aggressive progression and poor prognosis in ccRCC patients.

\section{Materials and methods}

\section{Patients and Variables}

A total of 367 ccRCC patients, who have underwent radical nephrectomy in the Department of Urology of Fudan University Shanghai Cancer Center (FUSCC) (Shanghai, China) from Aug 2008 to Sept 2017, were consecutively recruited in analyses, with electronic medical records or pathology reports available. Clinical and pathological parameters, specifically age at surgery, BMI, clinical manifestation, tumor laterality, tumor size, TNM stage, International Society of Urological Pathology (ISUP) grading classification and anthropometric measures of obesity on magnetic resonance imaging (MRI) $(\mathrm{n}=104)$, were summarized in Table 1. Tissue samples, including ccRCC and normal tissues, were collected during surgery and available from FUSCC tissue bank. All of the study designs and test procedures were performed in accordance with the Helsinki Declaration II. The Ethics approval and consent to participate of the current study was approved and consented by the ethics committee of FUSCC.

\section{Anthropometric measures of obesity}

BMI is defined as the weight $(\mathrm{kg})$ divided by the square of body height $(\mathrm{m})$, generally expressed in units of $\mathrm{kg} / \mathrm{m}^{2}$. The quantity of anthropometric measures of SAT area was measured by MRI with T2-weighted sagittal localization images. All images were identified at the level of the umbilicus (approximately L4-L5 marked in orange dotted line) for 367 patients in supine position in Figure 1, and then averaged for the final measurement. A in maroon or $\mathrm{P}$ in blue represents measurement of the anterior or 
posterior abdominal adipose thickness respectively, and anteroposterior diameter (AP) was measured in green lines [22]. Each MRI was reviewed by 2 experienced radiologists independently to determine the accuracy of measurement. The value of SAT was calculated as the sum of anterior abdominal fat and posterior abdominal fat $(\mathrm{SAT}=\mathrm{A}+\mathrm{P})$. The visceral obesity percentage was defined as $\mathrm{VAT} \%$, which was calculated using the formula VAT $\%=[(\mathrm{AP}-\mathrm{SAT}) / \mathrm{AP}]$ $\times 100 \%$.

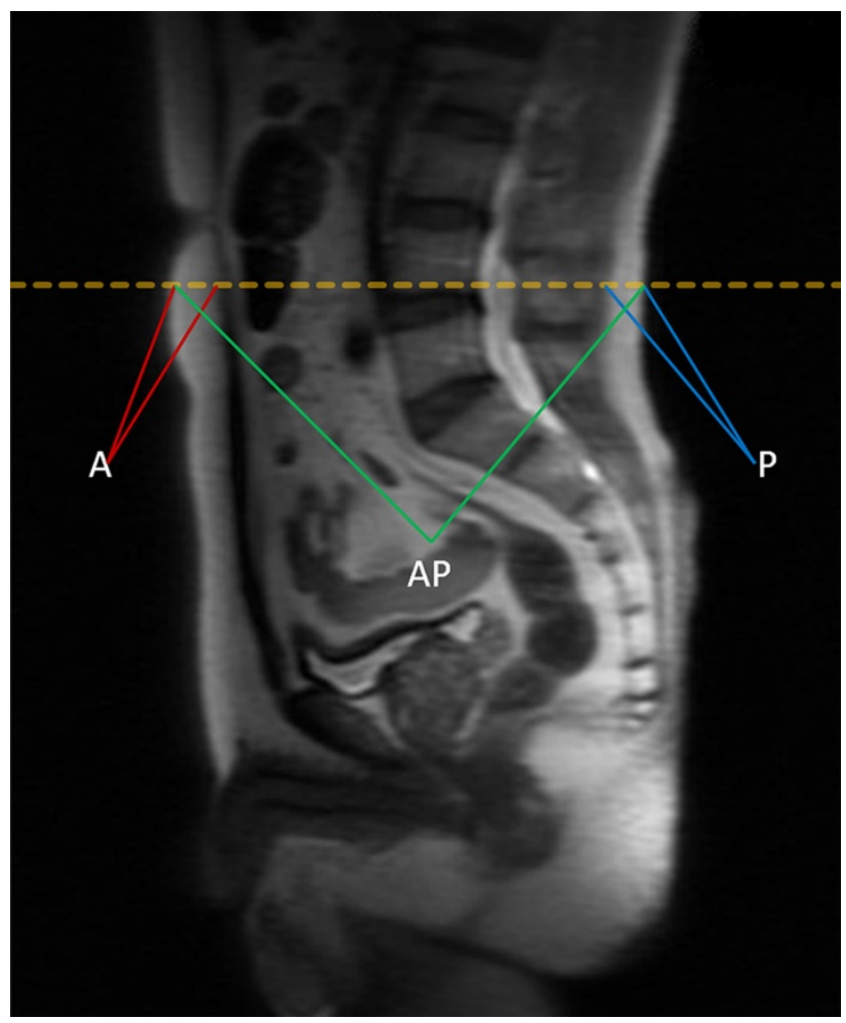

Figure 1. The quantity of anthropometric measures of SAT area was measured by MRI with T2-weighted sagittal localization images. All images were identified at the level of the umbilicus (approximately L4-L5 marked in orange dotted line) for 367 patients in supine position. $A$ in maroon or $P$ in blue represents measurement of the anterior or posterior abdominal adipose thickness respectively, and anteroposterior diameter (AP) was measured in green lines. The value of SAT was calculated as the sum of anterior abdominal fat and posterior abdominal fat $(S A T=A+P)$. The visceral obesity percentage was defined as VAT\%, which was calculated using the formula VAT $\%=[(\mathrm{AP}-\mathrm{SAT}) / \mathrm{AP}] \times 100 \%$

\section{Real-Time Quantitative PCR analysis}

Total RNA sequence was extracted using TRIzol reagent (Invitrogen, Carlsbad, CA) from 367 paired tumor and para-carcinoma normal samples. Total RNA reverse-transcribed reaction was performed using the SuperScript First-Strand cDNA Synthesis System (Invitrogen, Carlsbad, CA). ABI Prism 7900 Sequence Detector (Applied Biosystems) was utilized to realize Real-time PCR reactions. Forward PCR primers was 5'- GGCTGTGACCGG AACTGTG-3' and reverse primers was 5'AGGTCTCCAACTGGCATTAGAA-3'. According to SYBR Green PCR master mix (Applied Biosystems) manufacturer protocols, a total of $10 \mu \mathrm{L}$ reaction mixture was prepared for each test. Specific PCR operating cycles conditions for CD36 and $\beta$-action were performed as follows: denaturation at $95^{\circ} \mathrm{C}$ for 3 min, followed by 45 cycles of denaturation at $95^{\circ} \mathrm{C}$ for $20 \mathrm{sec}$, annealing at $60^{\circ} \mathrm{C}$ for $20 \mathrm{sec}$, extension at $68^{\circ} \mathrm{C}$ for $20 \mathrm{sec}$, and measurement at $80^{\circ} \mathrm{C}$ for $20 \mathrm{sec}$, followed by a final extension at $72^{\circ} \mathrm{C}$ for $5 \mathrm{~min}$. The CD36 mRNA expression was represented as $\Delta \mathrm{Ct}=$ $\mathrm{Ct}_{(\mathrm{CD} 36)}-\Delta \mathrm{Ct}_{(\beta \text {-actin). }}$. Relative expression in ccRCC was represented using the ratio of $C D 36$ expression in Tumor/Normal tissues (T/N). "Few CD36 expression", "Low CD36 expression", "Middle CD36 expression" and "High CD36 expression" denote the $\mathrm{T} / \mathrm{N}$ ratio of CD36 mRNA expression of less than 1 , more than 1 and less than 5 , more than 5 and less than 10 , and more than 10 , respectively. X-tile software was utilized to take the cut-off value: point of 5 and 10, in concordance of which overall participants were divided to three groups: CD36 expression high, middle and low.

\section{Statistical analysis}

To figure out the associations of different CD36 mRNA expression sets with clinicopathological characteristics, $X^{2}$-test was performed to compare the distribution of categorical data between groups. Pearson's correlation coefficient was utilized to quantify relations between BMI, VAT\%, SAT and levels of $C D 36$ expression. The primary end point was OS for patients who are alive for a certain period of time, which was evaluated from the date of radical nephrectomy to the date of death or last follow-up. Progression-free survival (PFS), as the secondary end point, was the length of time from the initiation of surgery until the date of progression or the start date of a second-line treatment or the date of death, whichever occurred first. The follow-up duration was estimated using the Kaplan-Meier method with $95 \% \mathrm{CI}$ and log-rank test in separate curves. Univariate and multivariate analysis were performed with Cox logistic regression models to find independent predictors. Cox regressions on 104 participants enrolled with available MRI scan were independently analyzed to evaluated confounding covariates including BMI, A, P, VAT\%, SAT on survival as supplements. Statistics analyses were performed with SPSS software (version 23.0, Inc, Chicago, IL, USA). All hypothetical tests were two-sided and $p$-values less than 0.05 were considered significant in all tests.

\section{Data processing of GSEA}

Datasets from the Cancer Genome Atlas database were implemented with GSEA method using the Category version 2.10.1 package. For each 
separate analysis, Student's-t-test statistical score was performed in consistent pathways and the mean of the differential expression genes was calculated. A permutation test with 1000 times was used to identify the significantly changed pathways. The adjusted $\mathrm{P}$ values (adj. P) using Benjamini and Hochberg (BH) false discovery rate (FDR) method by default were applied to correct for the occurrence of false positive results [23]. The significant related genes were defined with an adj. P less than 0.01 and FDR less than 0.25.

\section{Results}

In this study, research was conducted in three series. In the first series, progression and prognostic
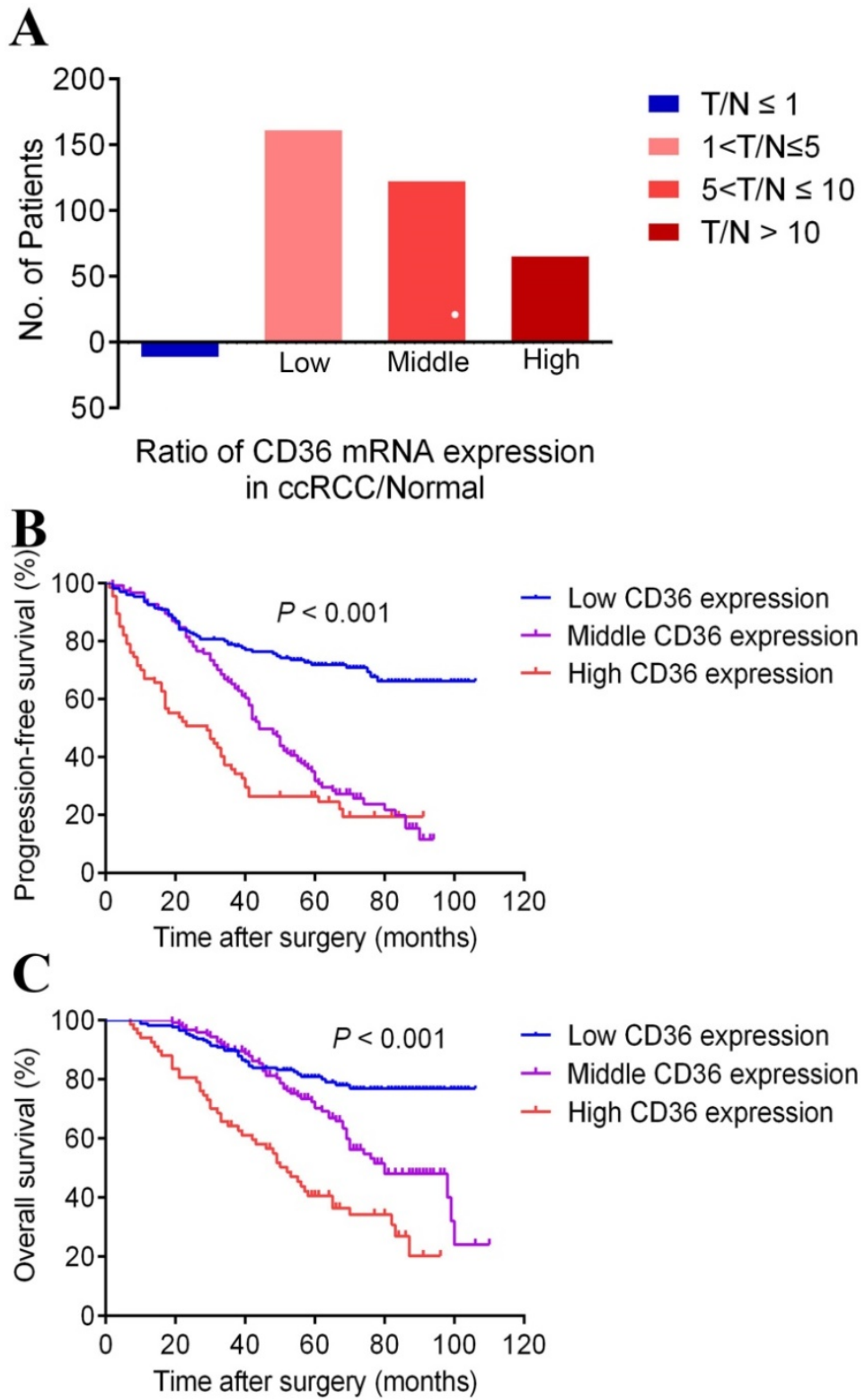

Figure 2. The percentage of different CD36 mRNA expression in patients with different $T / N$, which was define as the ratio of $C D 36$ expression in $\mathrm{ccRCC} /$ Normal tissue in panel A. Kaplan-Meier survival analyses on different CD36 expression groups with PFS (B) and OS (C) in the included $367 \mathrm{ccRCC}$ patients. Compared with middle and low CD36 expression, high CD36 expression is significantly correlated with poor PFS $(p<0.01)$ and OS $(p<0.01)$ value of CD36 mRNA expression in ccRCC patients were assessed; in the second series, relationships between $C D 36$ expression levels and anthropometric measures of obesity tissue were illustrated; in the third series, the role of VAT\% predicts survival benefits in ccRCC patients.

\section{Clinicopathological characteristics of the cohorts}

As shown in Table 1, patients with increased CD36 mRNA expression significantly correlated with advanced T $(p=0.003), \mathrm{N}(p<0.001)$, M stage $(p<0.001)$, and higher VAT\% $(p=0.004)$. Chi-square test showed that baseline data were balanced on the distribution of categorical data, including age at surgery, sex, BMI, clinical manifestation, laterality, ISUP grade and SAT $(p>0.05)$.

\section{Expression of CD36 in FUSCC}

To analyze the CD36 mRNA expression profile of ccRCC tumor tissue, Real-time PCR revealed participates distribution concerning the ratio of $\mathrm{T} / \mathrm{N}$ was dramatically different (3.5\% in few CD36 expression, $44.4 \%$ in low CD36 expression, $33.8 \%$ in middle CD36 expression and $18.3 \%$ in high CD36 expression) provided in Figure 2A.

\section{Cox regression analyses and survival outcomes of the cohorts}

In univariate and multivariate models, traditional prognostic factors, specifically $\mathrm{T}$, $\mathrm{N}$, and $\mathrm{M}$ stage, were still relevant to PFS and OS in ccRCC patients, indicating a fine representativeness of the population in the cohort of current research. Importantly, subgroups of CD36 expression (Low vs. middle) and CD36 expression (low vs. high) showed that CD36 amplification markedly associated with poor PFS $(p<0.001)$ and OS $(p<0.001)$ for ccRCC patients both in Cox logistic regression analysis. BMI, with $25 \mathrm{~kg} / \mathrm{m}^{2}$ cutoff, was only significant in PFS $(p=0.029)$ in univariate model of all Cox regression analyses. Besides, age at surgery and ISUP grade (1-2 vs. 3-4) were significant both in PFS (age: $p=0.014$, ISUP grade: $p<0.001$ ) and OS (age: $p=0.012$, ISUP grade: $p<0.001$ ) merely in univariate Cox regression. The other factors, including sex, clinical manifestation, tumor laterality and tumor size, were not assessed as prognostic indicators of PFS and OS in our study $(p>0.05)$ (Table 2 and Table 3). 
Table 1. Clinicopathological characteristics in relation to CD36 expression status.

\begin{tabular}{|c|c|c|c|c|c|}
\hline \multirow[t]{2}{*}{ Variable } & \multirow{2}{*}{$\begin{array}{l}\text { Entire } \\
\text { group } \\
(n=367)\end{array}$} & \multicolumn{3}{|c|}{ CD36 expression } & \multirow[b]{2}{*}{$\begin{array}{l}P \\
\text { value }\end{array}$} \\
\hline & & $\begin{array}{l}\text { Low } \\
\text { expression } \\
(n=176)\end{array}$ & $\begin{array}{l}\text { Middle } \\
\text { expression } \\
(n=124)\end{array}$ & $\begin{array}{l}\text { High } \\
\text { expression } \\
(n=67)\end{array}$ & \\
\hline $\begin{array}{l}\text { Age at surgery ( } y \text {, } \\
\text { mean } \pm S D)\end{array}$ & $\begin{array}{l}55.3 \pm \\
11.7\end{array}$ & $55.5 \pm 11.6$ & $57.0 \pm 12.2$ & $54.3 \pm 10.9$ & 0.145 \\
\hline $\operatorname{Sex}(n, \%)$ & & & & & 0.860 \\
\hline Male & $248(67.6)$ & $117(66.5)$ & $84(67.7)$ & $47(70.1)$ & \\
\hline Female & $119(32.4)$ & $59(33.5)$ & $40(32.3)$ & $20(29.9)$ & \\
\hline $\begin{array}{l}\mathrm{BMI}\left(\mathrm{kg} / \mathrm{m}^{2},\right. \\
\text { mean } \pm \mathrm{SD})\end{array}$ & $1.5 \pm 0.5$ & $1.5 \pm 0.5$ & $1.6 \pm 0.5$ & $1.4 \pm 0.5$ & 0.092 \\
\hline $\begin{array}{l}\text { Clinical } \\
\text { manifestation (n, } \\
\%)\end{array}$ & & & & & 0.829 \\
\hline Incidental & $246(67.0)$ & $118(67.0)$ & $85(68.5)$ & $43(64.2)$ & \\
\hline Symptomatic & $121(33.0)$ & $58(33.0)$ & $39(31.5)$ & $24(35.8)$ & \\
\hline Laterality (n, \%) & & & & & 0.092 \\
\hline Left & $182(49.6)$ & $92(52.3)$ & $52(41.9)$ & $38(56.7)$ & \\
\hline Right & $185(50.4)$ & $84(47.7)$ & $72(58.1)$ & $29(43.3)$ & \\
\hline $\begin{array}{l}\text { Tumor size }(\mathrm{cm} \text {, } \\
\text { mean } \pm S D)\end{array}$ & $5.2 \pm 2.4$ & $4.9 \pm 2.6$ & $5.5 \pm 2.4$ & $5.1 \pm 1.8$ & 0.051 \\
\hline $\begin{array}{l}\text { T stage at } \\
\text { presentation (n, } \\
\%)\end{array}$ & & & & & 0.003 \\
\hline $\mathrm{T} 1-\mathrm{T} 2$ & $300(81.7)$ & $150(85.2)$ & 105 (84.7) & $45(67.2)$ & \\
\hline T3-T4 & $67(18.3)$ & $26(14.8)$ & $19(15.3)$ & $22(32.8)$ & \\
\hline $\begin{array}{l}\text { N stage at } \\
\text { presentation (n, } \\
\%)\end{array}$ & & & & & $<0.001$ \\
\hline No & $326(88.8)$ & $162(92.0)$ & 115 (92.7) & $49(73.1)$ & \\
\hline N1 & $41(11.2)$ & $14(8.0)$ & $9(7.3)$ & $18(26.9)$ & \\
\hline $\begin{array}{l}\text { M stage at } \\
\text { presentation (n, } \\
\%)\end{array}$ & & & & & $<0.001$ \\
\hline M0 & $330(89.9)$ & $166(94.3)$ & $112(90.3)$ & $52(77.6)$ & \\
\hline M1 & $37(10.1)$ & $10(5.7)$ & $12(9.7)$ & $15(22.4)$ & \\
\hline ISUP grade (n, \%) & & & & & 0.023 \\
\hline $1-2$ & $175(47.7)$ & $92(52.3)$ & $61(49.2)$ & $22(32.8)$ & \\
\hline $3-4$ & $192(52.3)$ & $84(47.7)$ & $63(50.8)$ & $45(67.2)$ & \\
\hline \multicolumn{6}{|c|}{ Anthropometric measures of obesity on MRI $(n=104,28.3 \%)$} \\
\hline $\begin{array}{l}\text { No. of Patients } \\
(\%)^{*}\end{array}$ & $104(100)$ & $59(56.7)$ & $32(30.8)$ & $13(12.5)$ & \\
\hline $\begin{array}{l}\text { SAT (mm, mean } \\
\pm S D)\end{array}$ & $33.2 \pm 9.3$ & $35.1 \pm 10.7$ & $30.9 \pm 7.0$ & $30.5 \pm 4.1$ & 0.058 \\
\hline $\begin{array}{l}\text { VAT }(\%, \text { mean } \pm \\
\text { SD) }\end{array}$ & $83.6 \pm 3.2$ & $82.8 \pm 3.5$ & $84.5 \pm 2.5$ & $85.4 \pm 1.9$ & 0.004 \\
\hline
\end{tabular}

Survival curves suggested that patients with elevated CD36 mRNA levels showed poorer PFS and OS $(p<0.001)$. What's more, median PFS was 60 months and OS was 99 months in ccRCC patients. The median PFS in patients with middle and high CD36 expression levels were 44 and 29 months, and median OS were 80 and 52 months, respectively. Data was not available in patients with low CD36 expression due to their favorable prognosis, and median PFS and OS were not achieved by the time of last follow-up.

\section{VAT\% is a better obesity indicator for CCRCC}

Elevated CD36 mRNA expression correlated with higher VAT $(\%, p=0.004)$ in Table 1 , yet insignificant with BMI $\left(\mathrm{kg} / \mathrm{m}^{2}, p=0.092\right)$. Meanwhile, CD36 expression closely related to survival prognosis of ccRCC patients. To verify VAT\% a more accurate predictor than BMI, we measured relations between abdominal adipose distribution and CD36 mRNA expression. Pearson's correlation coefficient illustrated positive trend between $\mathrm{BMI}$ and $\mathrm{T} / \mathrm{N}$ ratio $(r=0.117, p=0.025)$ in Figure 3A. In parallel to BMI, $\mathrm{T} / \mathrm{N}$ ratio was positively correlated with the $\mathrm{VAT} \%$ $(r=0.465, p<0.001)$ (Figure 3B), while negatively to SAT $(r=-0.296, p=0.002)$ (Figure 3C).

Table 2. Univariate and multivariate Cox regression analyses of PFS in 367 enrolled ccRCC patients.

\begin{tabular}{|c|c|c|c|c|}
\hline & Univariate ana & halysis & $\begin{array}{l}\text { Multivariate } \\
\text { analysis }\end{array}$ & \\
\hline Covariates & HR $(95 \% \mathrm{CI})$ & $\begin{array}{l}\mathrm{P} \\
\text { value }\end{array}$ & HR $(95 \% \mathrm{CI})$ & $\begin{array}{l}\mathrm{P} \\
\text { value }\end{array}$ \\
\hline Age at surgery & $\begin{array}{l}1.015 \\
(1.003-1.027)\end{array}$ & 0.014 & $\begin{array}{l}1.006 \\
(0.993-1.019)\end{array}$ & 0.336 \\
\hline Sex (male vs. female) & $\begin{array}{l}0.774 \\
(0.567-1.058)\end{array}$ & 0.108 & $\begin{array}{l}0.837 \\
(0.605-1.160)\end{array}$ & 0.286 \\
\hline BMI $\left(<25 \mathrm{~kg} / \mathrm{m}^{2}\right.$ vs. $\left.\geq 25 \mathrm{~kg} / \mathrm{m}^{2}\right)$ & $\begin{array}{l}1.371 \\
(1.033-1.819)\end{array}$ & 0.029 & $\begin{array}{l}1.227 \\
(0.911-1.652)\end{array}$ & 0.178 \\
\hline $\begin{array}{l}\text { Clinical manifestation } \\
\text { (incidental vs. symptomatic) }\end{array}$ & $\begin{array}{l}1.010 \\
(0.751-1.359)\end{array}$ & 0.945 & $\begin{array}{l}0.970 \\
(0.711-1.324)\end{array}$ & 0.848 \\
\hline Laterality (left vs. right) & $\begin{array}{l}1.053 \\
(0.795-1.393)\end{array}$ & 0.720 & $\begin{array}{l}1.008 \\
(0.755-1.345)\end{array}$ & 0.957 \\
\hline Tumor size & $\begin{array}{l}1.033 \\
(0.979-1.090)\end{array}$ & 0.233 & $\begin{array}{l}1.049 \\
(0.987-1.115)\end{array}$ & 0.121 \\
\hline T stage (T1-T2 vs. T3-T4) & $\begin{array}{l}10.296 \\
(7.287-14.549)\end{array}$ & $<0.001$ & $\begin{array}{l}1.797 \\
(1.282-2.519)\end{array}$ & 0.001 \\
\hline $\mathrm{N}$ stage (N0 vs. N1) & $\begin{array}{l}12.415 \\
(8.356-18.444)\end{array}$ & $<0.001$ & $\begin{array}{l}3.340 \\
(1.915-5.826)\end{array}$ & $<0.001$ \\
\hline M stage (M0 vs. M1) & $\begin{array}{l}12.324 \\
(8.227-18.461)\end{array}$ & $<0.001$ & $\begin{array}{l}4.510 \\
(2.980-6.825)\end{array}$ & $<0.001$ \\
\hline ISUP grade (1-2 vs. 3-4) & $\begin{array}{l}3.019 \\
(2.225-4.098)\end{array}$ & $<0.001$ & $\begin{array}{l}1.544 \\
(0.867-2.750)\end{array}$ & 0.140 \\
\hline $\begin{array}{l}\text { CD36 expression (Low vs. } \\
\text { middle) }\end{array}$ & $\begin{array}{l}3.096 \\
(2.195-4.366)\end{array}$ & $<0.001$ & $\begin{array}{l}2.656 \\
(1.863-3.785)\end{array}$ & $<0.001$ \\
\hline $\begin{array}{l}\text { CD36 expression (low vs. } \\
\text { high) }\end{array}$ & $\begin{array}{l}4.873 \\
(3.300-7.196)\end{array}$ & $<0.001$ & $\begin{array}{l}3.244 \\
(2.152-4.890)\end{array}$ & $<0.001$ \\
\hline
\end{tabular}

Considering MRI scans were available only in 104 cases, in Supplementary Table 1 and Supplementary Table 2, multivariate Cox regression analyses of PFS and OS indicated that high VAT\% was significantly related with poor PFS $(\mathrm{HR}=2.56$, $p=0.042)$ and OS $(\mathrm{HR}=3.291, p=0.044)$, while BMI was not independent covariate affecting survival.

\section{Significant genes and pathway obtained by GSEA}

A total of 100 significant genes were obtained from GSEA, and the genes with positive correlation were plotted. Besides fatty acid metabolism, CD36 was found involved in the most significant pathways including UV response, angiogenesis and transforming growth factor beta (TGF- $\beta$ ) signaling pathways. The details were illustrated in Figure 4. 


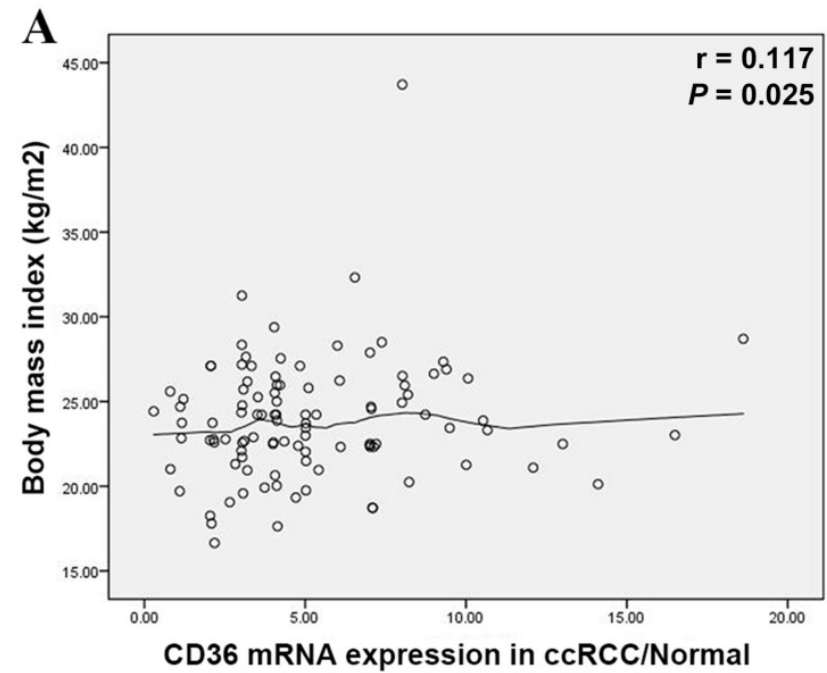

B
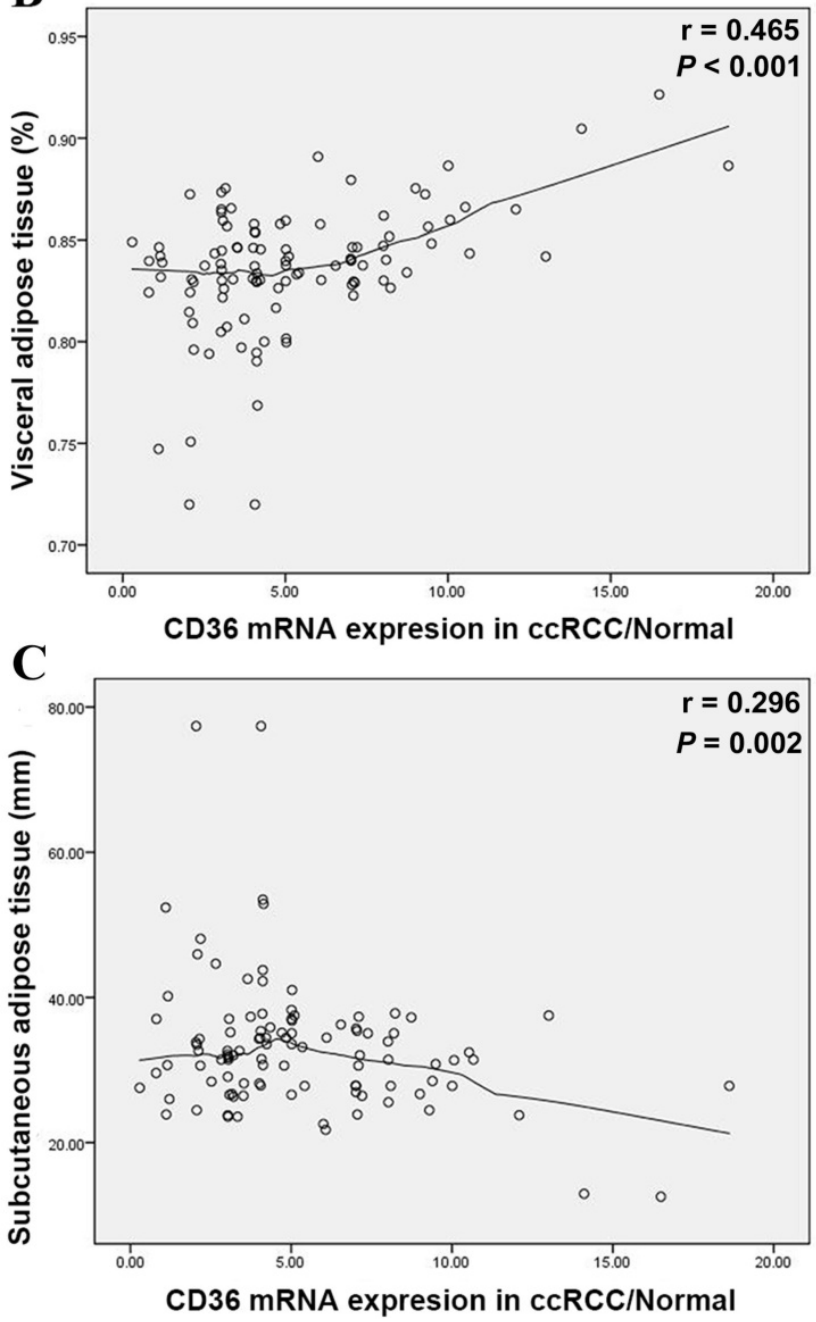

Figure 3. Scatterplots of the ratio of CD36 mRNA expression in ccRCC/Normal tissues compared with BMI (A), VAT\% (B) and SAT (C). Locally weighted scatterplot smoothing curves were fitted in plots. Pearson's correlation coefficient shows the T/N ratio was positively correlated with the BMI $(r=0.117, p=0.025)$, VAT\% $(r=0.465$, $p<0.001)$ and negatively correlated with SAT $(r=-0.296, p=0.002)$. VAT\%: visceral obesity percentage; SAT: subcutaneous adipose tissue.
Table 3. Univariate and multivariate Cox regression analyses of OS in 367 enrolled ccRCC patients.

\begin{tabular}{|c|c|c|c|c|}
\hline \multirow[b]{2}{*}{ Covariates } & \multicolumn{2}{|c|}{ Univariate analysis } & \multicolumn{2}{|c|}{ Multivariate analysis } \\
\hline & HR $(95 \% \mathrm{CI})$ & $\begin{array}{l}\mathrm{P} \\
\text { value }\end{array}$ & HR $(95 \% \mathrm{CI})$ & $\begin{array}{l}\mathrm{P} \\
\text { value }\end{array}$ \\
\hline Age a & $\begin{array}{l}1.018 \\
(1.004-1.033)\end{array}$ & 0.012 & $\begin{array}{l}1.015 \\
(0.999-1.030)\end{array}$ & 0.053 \\
\hline Sex $(m$ & $\begin{array}{l}0.922 \\
(0.639-1.331)\end{array}$ & 0.665 & $\begin{array}{l}1.028 \\
(0.698-1.514)\end{array}$ & 39 \\
\hline $\begin{array}{l}\text { BMI }\left(<25 \mathrm{~kg} / \mathrm{m}^{2} \mathrm{vs} .\right. \\
\left.\geq 25 \mathrm{~kg} / \mathrm{m}^{2}\right)\end{array}$ & $\begin{array}{l}1.255 \\
(0.892-1.766)\end{array}$ & 0.192 & $\begin{array}{l}1.082 \\
(0.751-1.559)\end{array}$ & 0.673 \\
\hline $\begin{array}{l}\text { nifestation } \\
\text { vs. symptomatic) }\end{array}$ & $\begin{array}{l}0.968 \\
(0.674-1.391)\end{array}$ & 0.861 & $\begin{array}{l}0.943 \\
(0.644-1.379)\end{array}$ & 0.761 \\
\hline Laterality (left vs. & $\begin{array}{l}1.030 \\
(0.735-1.443)\end{array}$ & 0.866 & $\begin{array}{l}0.873 \\
(0.615-1.238)\end{array}$ & 0.446 \\
\hline Tumor size & $\begin{array}{l}0.995 \\
(0.928-1.067)\end{array}$ & 0.890 & $\begin{array}{l}1.025 \\
(0.947-1.109)\end{array}$ & 0.542 \\
\hline T stage & $\begin{array}{l}12.148 \\
(8.359-17.654)\end{array}$ & $<0.001$ & $\begin{array}{l}1.572 \\
(1.011-2.445)\end{array}$ & 0.045 \\
\hline N stag & $\begin{array}{l}12.684 \\
(8.352-19.264)\end{array}$ & $<0.001$ & $\begin{array}{l}3.492 \\
(1.944-6.273)\end{array}$ & $<0.001$ \\
\hline$M$ stage (M0 v & $\begin{array}{l}11.554 \\
(7.618-17.525)\end{array}$ & $<0.001$ & $\begin{array}{l}5.270 \\
(3.256-8.532)\end{array}$ & $<0.001$ \\
\hline ISUP grade (1-2 vs. 3-4) & $\begin{array}{l}3.466 \\
(2.364-5.038)\end{array}$ & $<0.001$ & $\begin{array}{l}1.384 \\
(0.772-2.481)\end{array}$ & 0.276 \\
\hline $\begin{array}{l}\text { CD36 expression (Low vs. } \\
\text { middle) }\end{array}$ & $\begin{array}{l}2.113 \\
(1.383-3.229)\end{array}$ & 0.001 & $\begin{array}{l}1.925 \\
(1.239-2.992)\end{array}$ & 0.004 \\
\hline $\begin{array}{l}\text { CD36 expression (low vs. } \\
\text { high) }\end{array}$ & $\begin{array}{l}4.610 \\
(2.956-7.189)\end{array}$ & $<0.001$ & $\begin{array}{l}2.491 \\
(1.553-3.996)\end{array}$ & $<0.001$ \\
\hline
\end{tabular}

Abbreviations: OS: overall survival; ccRCC: clear cell renal cell carcinoma; HR: hazard ratio; CI: confidence interval; BMI: body mass index; ISUP: International Society of Urological Pathology.

\section{Discussion}

To clarify the effect of elevated CD36 mRNA expression of ccRCC, we detected anthropometric measures of adipose distribution on MRI and observed that CD36 mRNA amplification was significantly associated with increased VAT\%. More importantly, patients with elevated CD36 expression were exposed to poor PFS and OS after adjusting for all confounding covariates. It opens up a novel way for CD36 mRNA expression to affect the pathogenesis of ccRCC by underlying adipose metabolism variation.

Recently, several studies in related fields deeply demonstrated the role of adipose and related genes in tumor incidence and prognosis. In January 2017, Lin $\mathrm{H}$ et al. found that fatty acid oxidation was vital energy source for the metabolism and proliferation of malignant glioma cells [24]. It has upended long-held recognition on the primary energy source of tumor cells. Likewise, another research on Nature further suggested that, in addition to providing the "fuels", fat may also "pave the way" for the spread of cancer cells in lymphangiogenesis [25]. More importantly, a similar observation has been documented by Pascual et al., who revealed that $C D 36$ was responsible for the intake of fatty acid on the membrane of metastatic tumor cells, and metastasis was stopped after blockade of CD36 in mouse models [8]. Elevated CD36 was underpinned associated with individual obesity 
[5, 26, 27], especially with VAT\% in accord with previous studies emphasizing its clinical value $[20,28$, 29]. For example, it was proved that increased visceral-subcutaneous fat ratio was able to predict atherosclerosis [30, 31]. Interestingly, an inverse association between specific type of carcinoma and atherosclerosis has been reported [32], which made a plausible explanation from another perspective to clarify the relationship of CD36 and carcinogenesis.

A

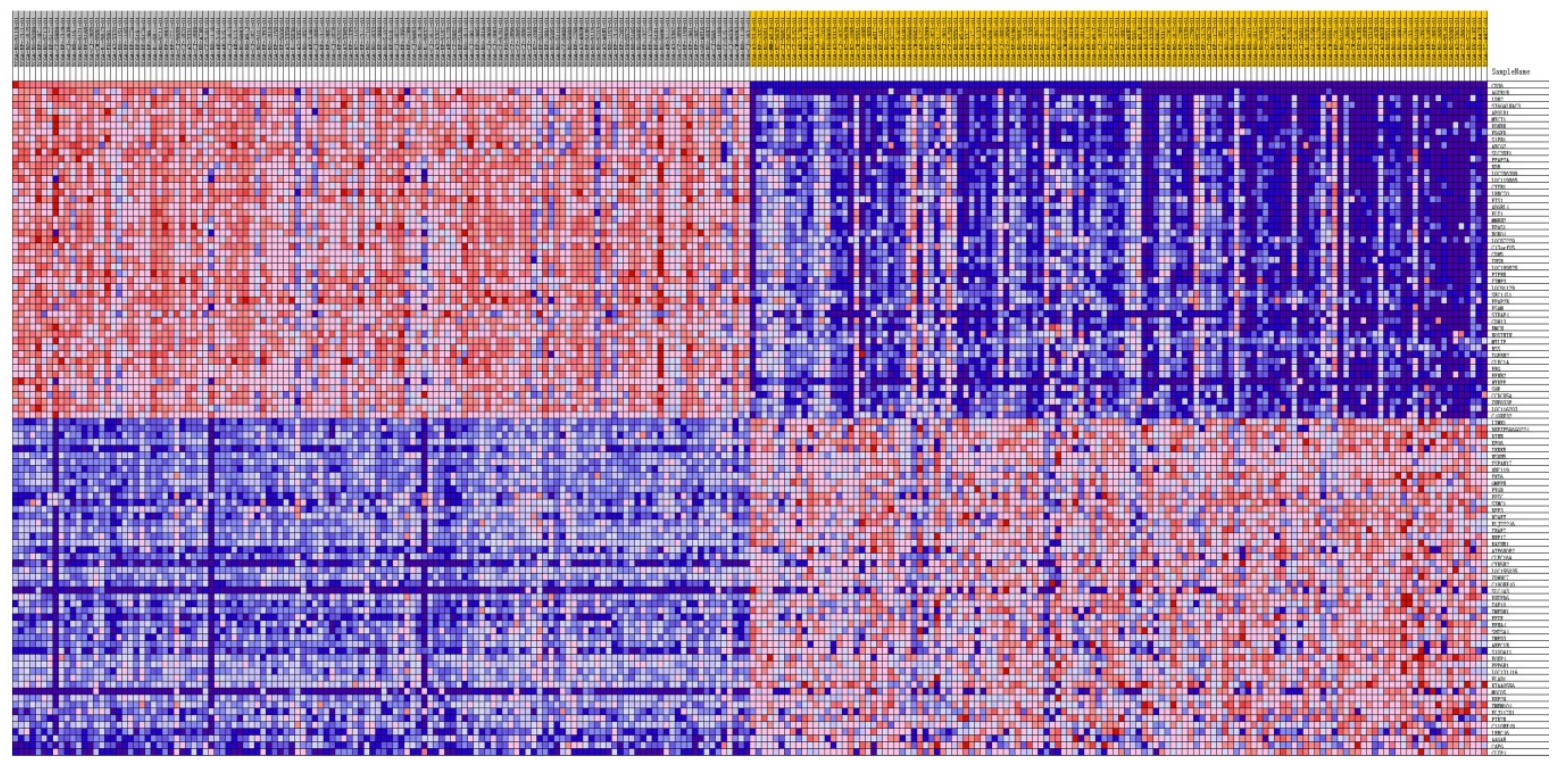

B

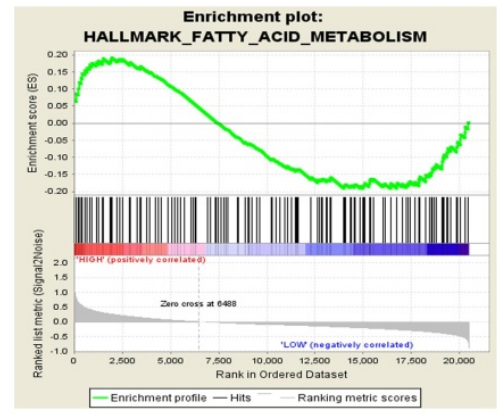

$\mathrm{E}$
C

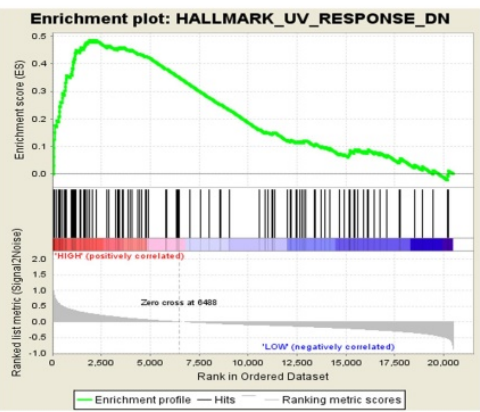

D

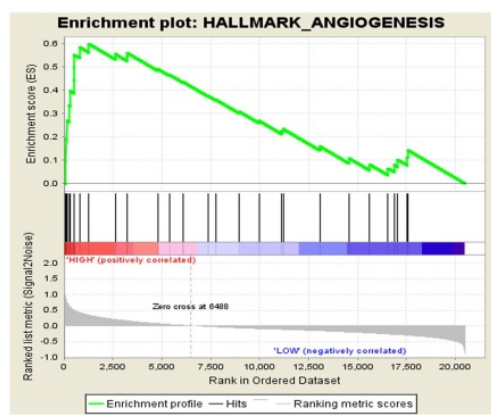

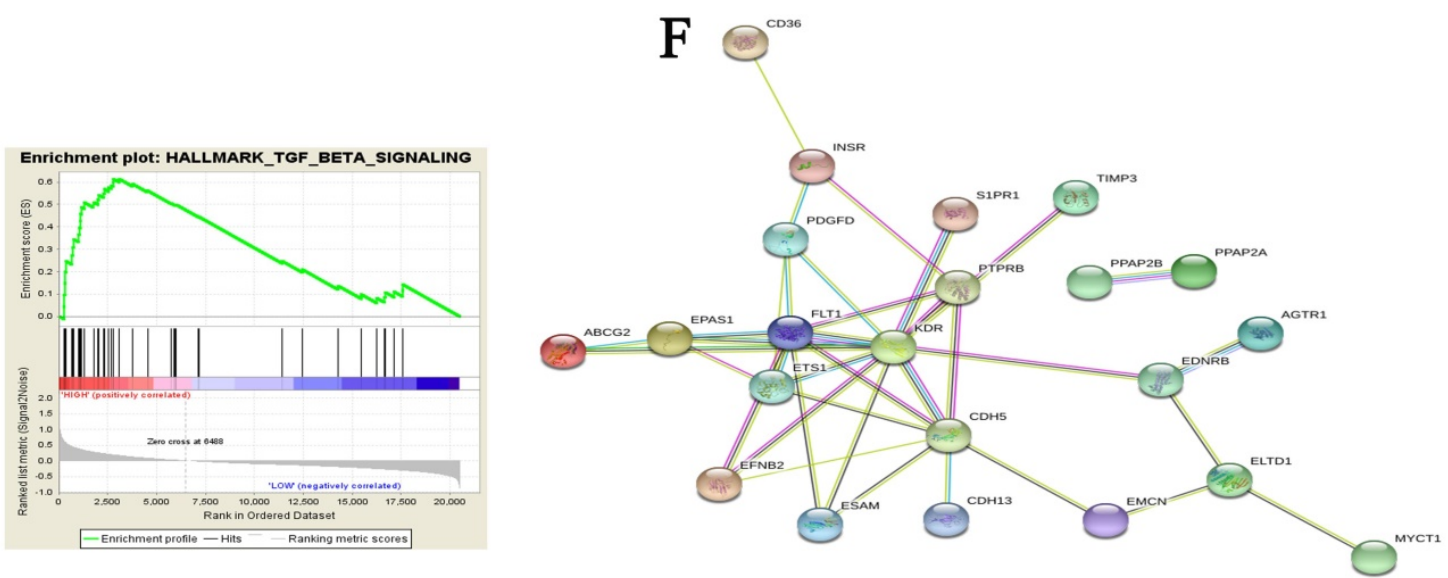

Figure 4. Datasets from public online database were implemented with GSEA method. For each separate analysis, Student's-t-test statistical score was performed in consistent pathways and the mean of the differential expression genes was calculated. A permutation test with 1000 times was used to identify the significantly changed pathways. The adjusted $\mathrm{P}$ values (adj. P) using Benjamini and Hochberg $(\mathrm{BH})$ false discovery rate (FDR) method by default were applied to correct for the occurrence of false positive results. The significant related genes were defined with an adj. P less than 0.01 and a FDR less than 0.25 . 
Although BMI has been demonstrated risk indicator of adiposity related to neoplasia $[9,33,34]$, as a traditional categorical variable, BMI may fail to adequately reflect the aggregate risk of ccRCC responses[35]. The role of BMI for individual body fat assessment was challenged for its rough estimation, including region, race diversity and failing to distinguish fat distribution [13-15]. However, relative to BMI, less is known concerning relationship between body adipose depots and tumorigenesis. Emerging evidence indicated that hormonal and metabolic disorders related to excess adiposity are largely driven by VAT [36-38]. Meanwhile, several investigations have documented and underpinned VAT as underlying mediator of adiposity triggering carcinogenesis, such as in colorectal adenomas [39], esophageal adenocarcinoma [40] and prostate cancer $[22,41]$. Our previous studies also suggested VAT correlated with high Fuhrman grade and pathological subtype of RCC [20,42], and it seemed to be more representative than $\mathrm{BMI}$ alone.

Despite the fact that computed tomography (CT) is used to be considered primarily standard imaging method for measurement of abdominal obesity, MRI is a highly predictive, accurate and safe modality to quantitatively assess body fat distribution [43-45], transcending the shortcomings of rough BMI cutoff. Therefore, as a routinely performed modality in ccRCC patients before surgery in our institution, MRI was utilized to measure SAT and then VAT\% calculated.

Meanwhile, GSEA analysis illustrated that CD36 associated with fatty acid metabolism, ultraviolet light response, angiogenesis and TGF- $\beta$ signaling pathways were enriched in ccRCC tissues. Besides lipid metabolism, growing evidence has demonstrated that CD36, as an endogenous anti-inflammatory cytokine, helps to explain tumorigenesis through the immunomodulatory actions of ultraviolet light [46]. Based on its participation in angiogenesis, one could speculate that CD36 involved in invasion and metastasis of tumor cells $[47,48]$. CD36 may also contribute to the activation of latent TGF- $\beta$, to enhance inflammatory responses, and to suppress immune responses [49].

Strength of our study lay in our first attempt to investigate the role of $C D 36$ as a prognostic factor of ccRCC. Relationship between CD36 and ccRCC was rarely documented, while it is noteworthy that $C D 36$ is estimated most expressed in many cancer patients. With this in mind, in the cohort of our study, we found dramatic CD36 mRNA quantity contrast between 367 paired tumor and adjacent normal tissues, and first demonstrated that ccRCC patients with elevated CD36 expression had shorter PFS and
OS, which was similar to the results of some other tumors $[50,51]$. On the other hand, we first figure out that certain distribution of abdominal adipose depots in ccRCC patents, particularly VAT\%, was positively correlated with over-expression of CD36 mRNA. In addition, $\mathrm{VAT} \%$ was access to predict progression and prognosis for ccRCC patients in this study, yet BMI failed. Therefore, it also provides a provoking thought that underlying adipose metabolism variation concerning $\mathrm{VAT} \%$ might clarify the correlation triggering carcinogenesis. To further explain underlying ability of invasion and metastasis of CD36, data from public database were implemented with GSEA analysis to identify significant genes and pathways.

At the same time, the main limitations proposed in this study are obvious as follows. First, our research failed to deeply clarify the underlying mechanism of CD36 involved in ccRCC. However, overall data indicate elevated CD36 mRNA expression as one of progressive indicators and close association with poor prognosis of ccRCC. It also provides a plausible explanation that high CD36 expression tied with advanced TNM stage and high ISUP grade, which were poor prognostic indicators of ccRCC. It may reflect to some extent that obesity-exposure causes cellular vital adipose metabolism variations and triggers carcinogenesis. While further investigations such as CD36 gene methylation status and models of protein co-expression are required for mechanism analysis in the future research. Second, the abdominal adipose thickness at the level of the umbilicus was measured by MRI in this study, and then VAT\% was directly calculated. This measurement method may have caused some calculation bias, with excess tissues including, bowel, bone, spinal fluid, muscle and visceral fat probably observed. Meanwhile, MRI scan was only available in 104 patients. Another limitation in this study is that generalizability and population variety may not conclusive enough to firmly support our results.

\section{Conclusion}

In conclusion, our study first reveal that elevated CD36 mRNA expression is positively correlated to distribution of abdominal adipose, particularly VAT\%, which, in addition, notably predicts poor prognosis in ccRCC patients.

\section{Acknowledgements}

This work is supported by Grants from the National Natural Science Foundation of China (Nos. 81202004, 81802525, 81471454), Shanghai Natural Science Foundation of China (No. 16ZR1406400), Science and Technology Municipal Commission of 
Shanghai, China (No. 16JC1405300), Shanghai Sailing Program (No. 17YF1402700) and the State Key Laboratory of Genetic Engineering (No. SKLGE-1605).

Authors' contributions: The work presented here was carried out in collaboration between all authors. YDW defined the research theme, discussed analyses, interpretation, and presentation. ZHL and ZJY developed the algorithm and performed the statistical analysis. XWH, QYY and WJ drafted the manuscript, carried out to record the clinical data, analyzed the data, and interpreted the results. WHK and WFN participated in reviewing all computed tomography scans, and co-worked on associated data collection. All authors read and approved the final manuscript.

Availability of data and material: The datasets during and/or analyzed during the current study available from the corresponding author on reasonable request.

Ethics approval and consent to participate: The Ethics approval and consent to participate of the current study was approved and consented by the ethics committee of Fudan University Shanghai Cancer center.

\section{Supplementary Material}

Supplementary figures and tables.

http://www.jcancer.org/v10p4522s1.pdf

\section{Competing Interests}

The authors have declared that no competing interest exists.

\section{References}

1. Siegel RL, Miller KD, Jemal A. Cancer statistics, 2018. CA Cancer J Clin. 2018; 68(1): 7-30.

2. Gupta K, Miller JD, Li JZ, et al. Epidemiologic and socioeconomic burden of metastatic renal cell carcinoma (mRCC): a literature review. Cancer Treat Rev. 2008; 34(3): 193-205.

3. Ljungberg, B., et al. The epidemiology of renal cell carcinoma. Eur Urol. 2011; 60(4): 615-21.

4. Pepino MY, Kuda O, Samovski D, et al. Structure-function of CD36 and importance of fatty acid signal transduction in fat metabolism. Annu Rev Nutr. 2014; 34: 281-303.

5. Hames KC, Vella A, Kemp BJ, et al. Free fatty acid uptake in humans with CD36 deficiency. Diabetes. 2014; 63(11): 3606-14.

6. Okamoto F, Tanaka T, Sohmiya K, et al.. CD36 abnormality and impaired myocardial long-chain fatty acid uptake in patients with hypertrophic cardiomyopathy. Jpn Circ J. 1998; 62(7): 499-504.

7. Pepino MY, Love-Gregory L, Klein S, et al. The fatty acid translocase gene CD36 and lingual lipase influence oral sensitivity to fat in obese subjects. J Lipid Res. 2012; 53(3): 561-6.

8. Pascual G, Avgustinova A, Mejetta S, et al. Targeting metastasis-initiating cells through the fatty acid receptor CD36. Nature. 2017; 541(7635): 41-45.

9. Albiges L, Hakimi AA, Xie W, et al. Body Mass Index and Metastatic Renal Cell Carcinoma: Clinical and Biological Correlations. J Clin Oncol. 2016; 34(30): 3655-3663

10. Renehan AG, Tyson M, Egger M, et al. Body-mass index and incidence of cancer: a systematic review and meta-analysis of prospective observational studies. Lancet. 2008; 371(9612): 569-78.

11. Motamedinia P, Korets R, Spencer BA, et al. Body mass index trends and role of obesity in predicting outcome after radical prostatectomy. Urology. 2008; 72(5): 1106-10

12. Campeggi A, Xylinas E, Ploussard G, et al. Impact of body mass index on perioperative morbidity, oncological, and functional outcomes after extraperitoneal laparoscopic radical prostatectomy. Urology. 2012; 80(3): 576-84.

13. Tomiyama AJ, Hunger JM, Nguyen-Cuu J, et al. Misclassification of cardiometabolic health when using body mass index categories in NHANES 2005-2012. Int J Obes (Lond). 2016; 40(5): 883-6.

14. Peterson MD, Al Snih S, Stoddard J, et al. Obesity misclassification and the metabolic syndrome in adults with functional mobility impairments: Nutrition Examination Survey 2003-2006. Prev Med. 2014; 60: 71-6.

15. Thomas EL, Frost G, Taylor-Robinson SD, et al. Excess body fat in obese and normal-weight subjects. Nutr Res Rev. 2012; 25(1): 150-61.

16. Ludescher B, Machann J, Eschweiler GW, et al. Correlation of fat distribution in whole body MRI with generally used anthropometric data. Invest Radiol. 2009; 44(11): 712-9.

17. Britton KA, Massaro JM, Murabito JM, et al. Body fat distribution, incident cardiovascular disease, cancer, and all-cause mortality. J Am Coll Cardiol. 2013; 62(10): 921-5.

18. Ibrahim MM. Subcutaneous and visceral adipose tissue: structural and functional differences. Obes Rev. 2010; 11(1): 11-8.

19. Mokdad AH, Ford ES, Bowman BA, et al. Prevalence of obesity, diabetes, and obesity-related health risk factors, 2001. JAMA. 2003; 289(1): 76-9.

20. Zhu Y, Wang HK, Zhang HL, et al. Visceral obesity and risk of high grade disease in clinical t1a renal cell carcinoma. J Urol. 2013; 189(2): 447-53.

21. Park $\mathrm{YH}$, Lee JK, Kim KM, et al. Visceral obesity in predicting oncologic outcomes of localized renal cell carcinoma. J Urol. 2014; 192(4): 1043-9.

22. Qu YY, Dai B, Kong YY, et al. Influence of obesity on localized prostate cancer patients treated with radical prostatectomy. Asian J Androl. 2013; 15(6): 747-52.

23. Subramanian A, Tamayo P, Mootha VK, et al. Gene set enrichment analysis: a knowledge-based approach for interpreting genome-wide expression profiles. Proc Natl Acad Sci USA. 2005; 102(43): 15545-50.

24. Lin H, Patel S, Affleck VS, et al. Fatty acid oxidation is required for the respiration and proliferation of malignant glioma cells. Neuro Oncol. 2017; 19(1): 43-54.

25. Wong BW, Wang $X$, Zecchin A, et al. The role of fatty acid beta-oxidation in lymphangiogenesis. Nature. 2017; 542(7639): 49-54

26. Abumrad NA. CD36 may determine our desire for dietary fats. J Clin Invest. 2005; 115(11): 2965-7.

27. Cui $\mathrm{W}$, Maimaitiyiming $\mathrm{H}$, Zhou $\mathrm{Q}$, et al. Interaction of thrombospondin 1 and CD36 contributes to obesity-associated podocytopathy. Biochim Biophys Acta. 2015; 1852(7): 1323-33.

28. Mizuno R, Miyajima A, Hibi $\mathrm{T}$, et al. Impact of baseline visceral fat accumulation on prognosis in patients with metastatic renal cell carcinoma treated with systemic therapy. Med Oncol. 2017; 34(4): 47.

29. Shuster A, Patlas M, Pinthus JH, et al. The clinical importance of visceral adiposity: a critical review of methods for visceral adipose tissue analysis. $\mathrm{Br} \mathrm{J}$ Radiol. 2012; 85(1009): 1-10

30. Bouchi $\mathrm{R}$, Takeuchi $\mathrm{T}$, Akihisa $\mathrm{M}$, et al. High visceral fat with low subcutaneous fat accumulation as a determinant of atherosclerosis in patients with type 2 diabetes. Cardiovasc Diabetol. 2015; 14: 136.

31. Higuchi S, Kabeya Y, Kato K. Visceral-to-subcutaneous fat ratio is independently related to small and large cerebrovascular lesions even in healthy subjects. Atherosclerosis. 2017; 259: 41-45.

32. Budczies J, von Winterfeld M, Klauschen F, et al. Comprehensive analysis of clinico-pathological data reveals heterogeneous relations between atherosclerosis and cancer. J Clin Pathol. 2014; 67(6): 482-90.

33. Lauby-Secretan B, Scoccianti C, Loomis D, et al. Body Fatness and Cancer--Viewpoint of the IARC Working Group. N Engl J Med. 2016; 375(8): 794-8.

34. Arnold M, Leitzmann M, Freisling $\mathrm{H}$, et al. Obesity and cancer: An update of the global impact. Cancer Epidemiol. 2016; 41: 8-15

35. Prentice AM, Jebb SA. Beyond body mass index. Obes Rev. 2001; 2(3): 141-7.

36. Kaaks R, Lukanova A, Kurzer MS. Obesity, endogenous hormones, and endometrial cancer risk: a synthetic review. Cancer Epidemiol Biomarkers Prev. 2002; 11(12): 1531-43.

37. Donohoe CL, Doyle SL, Reynolds JV. Visceral adiposity, insulin resistance and cancer risk. Diabetol Metab Syndr. 2011; 3: 12.

38. Wajchenberg BL. Subcutaneous and visceral adipose tissue: their relation to the metabolic syndrome. Endocr Rev. 2000; 21(6): 697-738.

39. Keum N, Lee DH, Kim R, et al. Giovannucci EL,et al. Visceral adiposity and colorectal adenomas: dose-response meta-analysis of observational studies. Ann Oncol. 2015; 26(6): 1101-9.

40. Massl R, van Blankenstein $\mathrm{M}$, Jeurnink $\mathrm{S}$, et al. Visceral adipose tissue: the link with esophageal adenocarcinoma. Scand J Gastroenterol. 2014; 49(4): 449-57.

41. Ohwaki K, Endo F, Hattori K. Abdominal obesity, hypertension, antihypertensive medication use and biochemical recurrence of prostate cancer after radical prostatectomy. Eur J Cancer. 2015. 51(5): 604-9.

42. Wang HK, Song XS, Cheng Y, et al. Visceral fat accumulation is associated with different pathological subtypes of renal cell carcinoma (RCC): a multicentre study in China. BJU Int. 2014; 114(4): 496-502.

43. Klopfenstein BJ, Kim MS, Krisky CM, et al. Comparison of 3 T MRI and CT for the measurement of visceral and subcutaneous adipose tissue in humans. Br J Radiol. 2012; 85(1018): e826-30.

44. Schaudinn A, Linder N, Garnov N, et al. Predictive accuracy of single- and multi-slice MRI for the estimation of total visceral adipose tissue in overweight to severely obese patients. NMR Biomed. 2015; 28(5): 583-90. 
45. Poonawalla AH, Sjoberg BP, Rehm JL, et al. Adipose tissue MRI for quantitative measurement of central obesity. J Magn Reson Imaging. 2013; 37(3): 707-16.

46. Craciun LI, DiGiambattista M, Schandené L, et al. Anti-inflammatory effects of UV-irradiated lymphocytes: induction of IL-1Ra upon phagocytosis by monocyte/macrophages. Clin Immunol. 2005; 114(3): 320-6.

47. Jiménez B, Volpert OV, Crawford SE, et al. Signals leading to apoptosis-dependent inhibition of neovascularization by thrombospondin-1. Nat Med. 2000; 6(1): 41-8.

48. Febbraio M, Hajjar D, Silverstein RL. CD36: a class B scavenger receptor involved in angiogenesis, atherosclerosis, inflammation, and lipid metabolism. J Clin Invest. 2001; 108(6): 785-91.

49. Crawford SE, Stellmach V, Murphy-Ullrich JE, et al. Thrombospondin-1 is a major activator of TGF-beta1 in vivo. Cell. 1998; 93(7): 1159-70.

50. Nath A, Chan C. Genetic alterations in fatty acid transport and metabolism genes are associated with metastatic progression and poor prognosis of human cancers. Sci Rep. 2016; 6: 18669.

51. Glatz JF, Luiken JJ, Bonen A. Membrane fatty acid transporters as regulators of lipid metabolism: implications for metabolic disease. Physiol Rev. 2010; 90(1): 367-417. 